\title{
Water in Agriculture: Improving Corn Production Practices to Minimize Climate Risk and Optimize Profitability
}

\author{
W. Brien Henry ${ }^{1}$ • L. Jason Krutz ${ }^{2}$ \\ Published online: 26 April 2016 \\ (C) The Author(s) 2016. This article is published with open access at Springerlink.com
}

\begin{abstract}
Recent improvements in climate modeling and consolidation within the agriculture and weather industries result in producers who are aware of relatively short-term weather patterns and can modify their cropping and irrigation strategies accordingly. Advances in breeding and genetics have improved stress tolerance of commercial corn hybrids and, along with seed treatment advances, allows seedlings to withstand cool, moist temperatures. Our work in the Mid-South USA region suggests that there are potential moisture savings with minor modifications to existing irrigation and agronomic practices. Data from over 14 farmer fields and four research stations over the 2013 to 2015 growing seasons suggest that by implementing minor irrigation modifications, we can improve yield by approximately 3 to $5 \%(8 \mathrm{bu} / \mathrm{A})$ and reduce the amount of water applied by $40 \%$ all while increasing profitability. Planting date, plant population, and hybrid selection can also be optimized to improve the profitability of the system and lower risk.
\end{abstract}

Keywords Climate · Corn · Irrigation · Agronomics · Risk · Food security

This article is part of the Topical Collection on Climate Change and Human Health

W. Brien Henry

BHenry@pss.msstate.edu

L. Jason Krutz

j.krutz@msstate.edu

1 MAFES, Mississippi State University, 32 Creelman, Box 9555, Mississippi State, MS 39762, USA

2 MSU Extension Service, Delta Research and Extension Center, Box 197, Stoneville, MS, USA

\section{Introduction}

At the most simple level, plants need water to grow. The philosophers of old first speculated on the relationship between water and plants. Aristotle noted that plants are made of water, then Empedocles clarified that plants need a combination of water, soil, and perhaps, other things [1]. This is true for all plants and especially for agricultural, commodity-based crops. Corn (Zea mays L.), in contrast to other crops, is particularly sensitive to water availability at critical reproductive growth stages [2]. Cotton (Gossypium hirsutum L.) is more drought-tolerant and grows well during the hottest, driest times of the summer. Grain sorghum (Sorghum bicolor (L.) Moench) is another crop that can shut down metabolically during extremely dry periods and then start growing again following rain events. Corn has neither cotton's drought tolerance nor grain sorghum's metabolic flexibility. Moisture availability during critical growth stages is extremely important to ensure optimal corn yields [3, 4]. With this in mind, improvements to both agronomic and irrigation strategies are crucial to improve and stabilize corn production.

\section{Response to Climate}

Climate is not static. The amount that it varies daily, weekly, yearly, and over decades changes over time. Corn producers hope to manage this variability in climate and weather during crop production by any means possible. Water availability is probably the most important weather variable to successful corn production. Options for producers to manage the risk associated with climate and resulting water availability include planting date, hybrid selection, and supplemental irrigation.

Making sense of climate and the variability associated with it is difficult, but that has not stopped people from trying. 
Falloon and Betts [5] discuss options for European producers to adapt to climate change as well as mitigating those potential effects. The authors suggest water, both too much in flooding, or not enough as summer drought is a primary source of concern. Another suggestion is to shift cropping regions northward if projected climate continues to warm. Olesen et al. [6] also discuss the climate-associated variability and the effect on cropping systems in Europe. They discuss temperature as precipitation in relation to the suitability of cropping in the northern and southern parts of the country but make special points about the enhanced yield variability in recent years. Makadho [7] focuses on corn production in Zimbabwe in response to climate change. Prolonged periods of drought and elevated temperatures result in highly risky cropping choices for an overwhelmingly impoverished group of producers. It is difficult to mitigate risk, even under irrigation, as growing seasons shorten and the likelihood of experiencing drought during critical reproductive phases of corn growth increases. Potentially shorter growing seasons in Africa would negatively affect corn production. One of the most recent and comprehensive works on climate variability and corn production is by Kellner and Niyogi [8]. Global weather trends over the past 30 years, and their specific influence on corn yields are noted.

Another modeling study by Isulam et al. [9] examines a host of future cropping scenarios in the US Central Great Plains. Irrigated corn production is modeled at 100, 75, and $50 \%$ ET demand coupled with three elevated temperature treatments during the growing season ranging between 1.4 and $5.4{ }^{\circ} \mathrm{C}$. The summary of this work was that in order to keep yield constant as temperature increased, more supplemental irrigation would be needed. This is troubling because for the Central Great Plains region, water is highly limited. Specifically, groundwater from the Ogallala aquifer is in rapid decline [10]. If the goal is to maintain current corn production levels but irrigation water is in decline while climate variability is increasing, this results in enhanced risk and potentially unsustainable corn production in this region.

Modelers and climatologists study long-term weather trends, while agronomists, breeders, and soil scientists attempt to optimize cropping strategies. The convergence of these disciplines has steadily increased over time. The past 2 years brought us mergers involving weather businesses and the two of the largest agriculture companies: Monsanto purchased Climate Corporation for almost a billion US dollars in 2013 [11•] and Pioneer entered into a collaboration with DTN/ Progressive Farmer in 2014. These ventures emphasize the importance of data management and premium weather content in relation to farming and agricultural decision making. Industry appears to realize the importance of both weather and climate in long-term food production.

\section{Cropping Sustainability}

Corn production requires significant amounts of water. Corn water consumption has been studied extensively because corn is an important grain crop for both human and livestock consumption worldwide. The specifics when this moisture is received during the growing season are of critical importance [12]. Sustainability is a concept that has received considerable attention recently related to agricultural production systems. This term is used exhaustively in the literature, and it is often associated in popular press with something about which one should feel guilty. Guilt is a much more comfortable feeling than hunger. We can feel guilty, or bad, about the depletion of a water source, be that an aquifer, reservoir, stream, or river, but the resulting collapse of an agricultural production system could leave us feeling hungry. Hunger is an entirely different feeling, the one that we have gotten away from in most developed nations. Food security, at least for the USA, has been a national focus with the creation of national organizations to support agricultural research like the USDA-Agriculture Research Service. National granting agencies like USDANIFA, the National Institute of Food and Agriculture, are dedicated to funding agriculture-specific research projects. Nationalized efforts to stabilize food research and production have resulted in bountiful, consistent harvests and historically low food prices. Agricultural sustainability, in particular with respect to water availability, is not something that should be taken lightly. Groundwater depletion is a real problem as documented by Scanlon et al. [10] in the US Southern High Plains and Central Valley of California. It is a relatively simple concept: using groundwater at a rate greater than natural recharge leads to depletion of said reserves [13, 14•].

Arid places, like regions of the US Midwest in California, Arizona, and Colorado lend themselves to production because disease in these dry environments is limited. Because of an overall lack of humidity, nighttime temperatures are cool and the resulting low-stress conditions favor crop production. However, crops in these regions usually require supplemental irrigation and the source is often groundwater. Globally, the issues surrounding recharge are quite similar; we are pumping groundwater for irrigation faster than natural recharge rates [15].

\section{Limited Irrigation Research}

Documenting the extremes in climate includes both temperature [16] and drought as well as the diminishing irrigation resources throughout the world $[10,15]$. It is one thing to document changes in climate and even the frequency or rate and magnitude of these changes over the past 30 years in response to crop yields [8], but the question remains: what is to be done about it? A great deal of work has been conducted in the Central Great Plains region of the USA [17]. As 
irrigation water becomes limited, the flow rate of wells declines to the point that the well capacity can no longer support fully irrigated crop production. Measures to enhance irrigation efficiency in this region include drop nozzles which release water less than a meter above the ground, well beneath the arm of the center pivot, thereby reducing the distance the water falls and minimizing the influence of evaporation. Other solutions include selecting a crop that requires less water or only planting a portion of the potentially irrigated field and maximizing the available water on only a portion of the area under the center pivot. A great deal of research has been conducted on the timing of irrigation for optimizing corn production. Throughout the Kansas, Colorado, and Nebraska regions of the Central Great Plains of the USA, multiple site years of data suggest that delaying the onset of irrigation until 2 weeks prior to tasseling is likely to result in comparable yields to fully irrigated corn most years [17]. Withholding irrigation early in the season may stress the plants somewhat, but the earlyseason stress may encourage the root system to expand its search of water, thereby improving moisture-scavenging ability later in the season once plants enter the reproductive growth phase.

Dryland cropping research often focuses on the sequence of crops and the efficient utilization of stored soil moisture as well as moisture received during the season $[18,19 \bullet]$. Dryland corn is a risky crop because of substantial input costs for fertilizer and seed. Additionally, a corn crop's success or failure is heavily related to precipitation or moisture received during the critical time period around tasseling. In the absence of irrigation, an extended period of drought in the middle of the growing season is catastrophic. Production risk and low commodity prices will negatively influence producer's decisions to grow corn in arid regions of the country.

\section{Corn Research in the Mid-South USA Region}

The USA produces roughly $40 \%$ of the world's corn supply and, in 2014, generated 14.2 billion bushels of corn [20] at $171 \mathrm{bu} / \mathrm{A}$ on 83 million acres that were harvested for grain. Climate variation affects these yields greatly. Yield in the USA was approximately $50 \mathrm{bu} / \mathrm{A}$ (or $30 \%$ ) lower in 2012. This reduction was largely attributable to heat and drought during critical reproductive growth phases throughout the corngrowing portion of the country. Corn grows well in Mississippi, especially in rotation with broadleaf crops like in a soybean (Glycine max (L.) Merr.) or cotton. This part of the country receives approximately $54 \mathrm{in}$. $(137 \mathrm{~cm})$ of annual precipitation. As we have established previously, corn needs water to yield well and because water is relatively plentiful in this subtropical environment, corn is a stable, profitable crop. Water is not, however, unlimited so many of our researchable topics investigate water conservation [21].

\section{Irrigation Tubing Hole Size}

Because the ground is flat in the Mississippi Delta of the MidSouth, furrow irrigation, while inefficient, is the predominant method of delivering water in this region. Water is pumped from wells and large plastic tubes fill with water along the edge of the field. Current research investigates Pipe Hole And Universal Crown Evaluation Tool (PHAUCET)/Pipe Planner, surge valves, and irrigation timing. Holes are then punched in the plastic tube, and water drains out into the rows running slowly down the field from one end to the other. Getting water across the field from one end to the other is called a run. PHAUCET and Pipe Planner are useful to irrigate irregularly shaped fields. Instead of punching uniform holes in the irrigation tubing, parts of the field with long irrigation runs receive large holes while parts of the field with a short irrigation run receive small holes. In theory, the irrigation water flows from the irrigation tubing non-uniformly according to hole size and reaches the end of the field in a uniform manner so that little water is wasted running out the end of the field. The slope of the field must be taken into account as well as the soil type and length of the field. These data are used to predict optimal hole size to punch into the irrigation tubing with respect to varying field size, slope, and soil composition.

\section{Surge Valves}

Surge valves are another tool to optimize irrigation and conserve water. Furrow irrigation runs can take a long time to get water completely across a field. This is mostly caused by long fields and cracking soil types. Failing to get water from one side of the field to the other leaves corn at the end of the field at a water deficit. However, water exiting the field does not signify a completely successful irrigation event. If the irrigation duration is long enough, the area of the field immediately adjacent to the irrigation tubing may have excessive water seepage draining down through the soil profile below the root zone. This is wasted water that is unusable by the plants. Conversely, the tail end of the field furthest from the irrigation tubing will have water running out but may not be sufficiently wetted down into the soil profile fully saturating the rooting zone. Finding a balance between these two extremes, wasted water and overly saturated soil on the front of the field and dry soil at the tail end of the field, is our goal. Surge valves help accomplish a more uniform wetting of the field. Fields are divided into half, and the flow rate of water into the field is increased greatly. The water surges down the field, and then a valve flips and the other side of the field is watered. As the second half of the field is watered, the water in the first half of the field soaks into the soil. This process is repeated a number of times until the field is uniformly wetted. 


\section{Irrigation Timing}

Finally, irrigation timing is a third water savings strategy. This line of research is relatively simple because much of it has already been conducted in the Midwest as was described previously in the manuscript. We must determine if it works here in our environment with our irrigation techniques and on our soil types. Local agricultural consultants frequently suggest watering at the first sign of wilting, regardless of soil moisture levels, which for the most part are unknown. Over-watering can reduce yields, limit root growth, and reduce the effectiveness of early-season fertilizer applications. These types of data have been difficult to gather over the past couple of years because we have experienced wetter than usual growing seasons and frequent rainfalls throughout our summer months. Soil moisture sensors are needed at the farm level. So many irrigation decisions have historically been made with zero information about moisture in the soil profile. Whether initiating or terminating irrigation, knowledge of the moisture within the soil profile allows the producer to make an informed, confident decision.

\section{Agronomic Solutions}

Heat and drought limit corn productivity in the Mid-South USA region. This is not unique to the Mid-South but is typically the case for corn producers globally. What is unique to the Mid-South is a very long growing season combined with higher probabilities of heat and drought in June, July, and August. The length of our growing season could allow us to alter other management decisions such as planting date, hybrid selection, relative maturity adjustments, and/or plant populations.

\section{Early Planting}

Avoiding the stressful periods of the summer by shifting the production window forward is a potential way to stabilize corn yield. The goal of early planting is to allow the corn plant to enter critical reproductive phases prior to the onset of the greatest probability for heat and drought in June and July (Fig. 1). However, early planting introduces risk associated with cool soil temperatures (below $50^{\circ} \mathrm{F}$ or $10^{\circ} \mathrm{C}$ ), wet soil, soil compaction, and freeze damage.

For instance, early planting on 1 March would initially expose the young plants to frost, but they would typically pollinate under a somewhat lower probability of dry weather. Conversely, planting later in mid-April removes the risk of frost but increases the probability of exposure to extended periods of drought during tasseling 60 days later. Our goal is to adjust the planting date to optimize plant growth and minimize risk while maximizing yield. Finding this balance is a challenge for growers. The risk of early planting is difficult to evaluate because freeze damage to newly emerged corn likely has minimal impact on yield. However, freeze damage to larger plants with five to six collared leaves could cause substantial yield reduction. Soil compaction is another issue of consideration, especially for early planting in moist soils. Farmers are using larger equipment to help them manage more acres. In our Mid-South region, the largest planters can cover 24 rows (or 60 to $76 \mathrm{ft}$ ) at a time. Using large equipment improves efficiency, but the weight of these machines penalizes growers for planting in wet soil. Soil compaction resulting from heavy equipment was a problem in 2015. Lighter planters and smaller, lighter tractors are needed to capitalize on getting planted in wet conditions.

\section{Relative Maturity}

In addition to moving the planting and production window forward, we have also recently investigated shortening this window by using hybrids that mature sooner. Relative maturity (RM) is a reference to the length of growing season or how many heat units it takes for a crop to reach maturity. Typical hybrids for our Mid-South region have a 115 to 120 RM compared with Iowa or Minnesota where most corn is 100 to 110 RM. In theory, the longer growing season in the Mid-South allows the plants to capture more sunlight, conduct more photosynthesis, fix more starch, and increase yield. However, longer maturing hybrids tassel in June or July when there is a high probability of heat and drought. These growthlimiting periods, both with and without supplemental irrigation, result in plant stress that limit yield. We hope to shorten the season by selecting 95 to110 RM hybrids. Two years of preliminary data are promising compared with yields of our standard 115-120 RM hybrids. Producer's acceptance of these strategies as well as our irrigation strategies is critical for adoption. Producers feel much more comfortable on adopting new technology if they can see it on a large-scale, field-sized test plot.

\section{Corn Population}

Because of advances by corn breeders for enhanced stress tolerance [22], increasing the population is a method to increase yield. This strategy fits well alongside early planting because increased moisture availability and decreased likelihood of heat and drought favor higher plant populations. Corn typically produces a single harvestable ear on a single stalk, so the most direct way to generate more ears is to add more plants. More ears, in the absence of limiting stress factors like heat, drought, or disease, equal to more grain. Our data from multiple locations over the 2013 to 2015 growing seasons appear to favor populations between 30,000 and 35,000 plants per acre. These sites are rain-fed, and these populations exceed what is currently grown by most corn producers in our region. 
Fig. 1 Historical weather data from Stoneville, MS, indicating the probability of experiencing cold (temperatures 32 or $28^{\circ} \mathrm{F}$ ) or drought (number of consecutive days 15 or 20 without a rainfall event greater than 0.1) [4]. The horizontal bars represent the 60 day windows between planting and tasseling for planting dates of 1 March and 20 April
Temperature and Rainfall Data

1971-2010

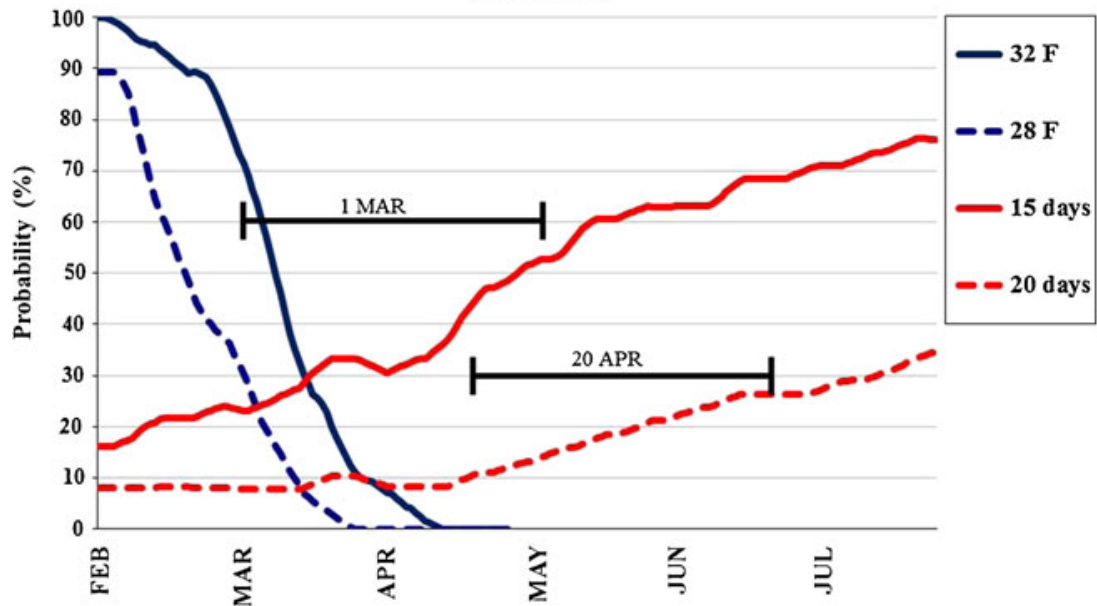

The summer precipitation, for the most part, has been average to above average at these sites and in only one of the six site years did we see a yield reduction attributable to elevated plant population. This yield reduction at elevated populations was only present in one of the three hybrids tested providing evidence that there is variation among commercially available hybrid's ability to tolerate stress and high populations.

\section{Hybrid Selection}

Genetic variability and breeding for improved corn hybrids is a massive undertaking that has resulted in improved stress tolerance and increased yields [22]. Heat and drought stress affect hybrids differently. Planting early into cool, moist soils can also affect root and shoot growth of hybrids differentially. If a producer decided to plant early to avoid heat and drought stress, then ideal hybrids would have enhanced early-season vigor, uniform and rapid emergence, and rapid growth in cooler temperatures. Evaluations of early-season cold tolerance did not exist in the literature so we screened 33 commercially available hybrids for above and below ground growth [23]. Various temperature regimes ranging from optimal to very cold resulted in a range of root and shoot data. Hybrids were classified into four groups ranging from cold-tolerant to coldsusceptible. The expectation was that a producer could select a cold-tolerant hybrid for early planting. A second trial incorporated a subset of 17 of these 33 hybrids of varying cold tolerance. They were initially grown at an optimal temperature, and then a very cold temperature regime was imposed to simulate an early-season "cold snap" [24••] as well as various drought stress regimes [25]. Data were analyzed similarly as in the previous trial, and variability among hybrid's response to cold was detected. Good growth characteristics at cool temperatures does not automatically mean that these hybrids will yield well, but if we evaluate the regional yield data alongside these cold screens, we can select hybrids that not only grow well in cool conditions but also yield well. Selecting the correct hybrid, in theory, should optimize our chances of success should we plant early. Field validations of these trials are planned for the 2016 growing season.

\section{Conclusions}

Water is critical for agricultural production. We must use it wisely in agricultural production and conserve our irrigation reserves. By optimizing our agronomic systems and irrigation strategies, we can overcome intense periods of heat and drought and possibly stabilize yield over time. Recent improvements in climate modeling and consolidation within the agriculture and weather industries result in producers who are keenly aware of relatively short-term weather patterns and can modify their cropping strategies accordingly. Advances in breeding and genetics have improved stress tolerance of commercially available corn hybrids, and that, along with seed treatment advances, allows seedlings to withstand cool, moist temperatures. Our work in the Mid-South USA region suggests that we can find moisture savings with minor modifications to existing irrigation and agronomic practices. Data from over 14 farmer fields and four research stations over the 2013 to 2015 growing seasons suggest that by implementing these irrigation improvements, we can improve yield by $8 \mathrm{bu} / \mathrm{A}$ and reduce the amount of water applied by $40 \%$ all while increasing profitability. Planting date, plant population, and hybrid selection can be optimized to improve the profitability of the system all while lowering risk. Applying water at the proper time, rate, and amount as well as cropping with climate awareness will result in sustainable and more profitable systems and enhanced food security for our world. 


\section{Compliance with Ethical Standards}

Conflict of Interest On behalf of all authors, the corresponding author states that there is no conflict of interest.

Open Access This article is distributed under the terms of the Creative Commons Attribution 4.0 International License (http:// creativecommons.org/licenses/by/4.0/), which permits unrestricted use, distribution, and reproduction in any medium, provided you give appropriate credit to the original author(s) and the source, provide a link to the Creative Commons license, and indicate if changes were made.

\section{References}

Papers of particular interest, published recently have been highlighted as:

- Of importance

-• Of major importance

1. Bostock, D. Space, time, matter, and form: essays on Aristotle's physics. OUP: Oxford, 2006.

2. Nielsen DC, Vigil MF, Benjamin JG. The variable response of dryland corn grain yield to soil water content at planting. Agric Water Manag. 2009;96:330-6.

3. Kellner O, Niyogi D. Agroclimatology. Encyclopedia of natural resources. Air. 2014. doi:10.1081-ENRA-120047622.

4. Watkins, T. Assessment of weather-related risk associated with early corn planting in Mississippi. MS thesis, Mississippi State, Mississippi State University, MSU. May 2014.

5. Falloon P, Betts R. Climate impact on European agriculture and water management in the context of adaptation and mitigation-the importance of an integrated approach. Sci Total Environ. 2010;408:5667-87. doi:10.1016/j.scitotenv. 2009.05.002.

6. Olesen JE, Trnka M, Kersebaum KC, Skjelvag AO, Seguin B, Peltonen-Sainio P, et al. Impacts and adaptation of European crop production systems to climate change. Eur J Agron. 2011;34:96112. doi:10.1016/j.eja.2010.11.003.

7. Makadho JM. Potential effects of climate change on corn production in Zimbabwe. Climate Research. 1996;6:147-51. http://www. int-res.com/articles/cr/6/c006p147.pdf.

8. Kellner O, Niyogi D. Climate variability and the U.S. Corn Belt: ENSO and AO episode-dependent hydroclimatic feedbacks to corn production at regional and local scales. Earth Interact. 2015;19:132. doi:10.1175/EI-D-14-0031.1.

9. Isulam A, Ahuja LR, Garcia LA, Ma L, Saseendran A, Trout T. Modeling the impacts of climate change on irrigated corn production in the Central Great Plains. Agric Water Manag. 2012;110:94-108. doi:10.1016/j.agwat.2012. 04.004.

10. Scanlon BR, Faunt CC, Longuevergne L, et al. Groundwater depletion and sustainability of irrigation in the US High Plains and Central Valley. Proc Natl Acad Sci U S A. 2012;109(24):9320-5. doi:10.1073/pnas.1200311109.

11. Upbin B. Monsanto buys climate Corp for $\$ 930$ million. Forbes Tech. 2013;2. This is the first review of screening commercially available corn germplasm for cold tolerance. Farmers can use this information.

12. Nielsen DC, Halvorson AD, Vigil MF. Critical precipitation period for dryland maize production. Field Crop Res. 2010;118:259-63.

13. Döll P, Hoffmann-Dobrev H, Portmann FT, Siebert S, Eicker A, Rodell M, et al. Impact of water withdrawals from groundwater and surface water on continental water storage variations. J Geodyn. 2012;59-60:143-56. doi:10.1016/j.jog.2011.05.001.

14. Crosbie RS, Pickett T, Mpelasoka FS, Hodgson G, Charles SP, Barron OV. An assessment of the climate change impacts on groundwater recharge at a continental scale using a probabilistic approach with an ensemble of GCMs. Clim Chang. 2013;117:4153. doi:10.1007/s10584-012-0558-6. Understanding impact of global recharge through probabilistic models is critical for assessing water availability long term.

15. Scanlon BR, Keese KE, Flint AL, Flint LE, Gaye CB, Edmunds $\mathrm{WM}$, et al. Global synthesis of groundwater recharge in semiarid and arid regions. Hydrol Process. 2006;20:3335-70. doi:10.1002/ hyp.6335.

16. Loikith PC, Broccoli AJ. The influence of recurrent modes of climate variability on the occurrence of winter and summer extreme temperatures over North America. J Clim. 2014;27:1600-18. doi: 10.1175/JCLI-D-13-00068.1.

17. Schneekloth JP, Nielsen DC. Irrigation capacity impact on limited irrigation management and cropping systems. Proceedings of the 23rd annual Central Plains irrigation conference, Burlington, CO. CPIA, Colby, KS 2011.

18. Duivenbooden NV, Pala M, Studer C, Bielders CL, Beukes DJ. Cropping systems and crop complementarity in dryland agriculture to increase soil water use efficiency: a review. Neth J Agric Sci. 2000;48(3):213-36. doi:10.1016/S1573-5214(00)80015-9.

19. Nielsen D, Vigil M. Searching for synergism in dryland cropping systems in the Central Great Plains. Field Crop Res. 2014;158:34 42. doi:10.1016/j.fcr.2013.12.020. Synergism is babble-speak related to cropping systems research. Water is the critical component, not magic or synergism.

20. USDA Crop Production 2014 Summary. Agricultural statistics service. Jan 2015. Accessed: 3 Jan 2016 http://usda.mannlib. cornell.edu/usda/nass/CropProdSu//2010s/2015/CropProdSu01-12-2015.pdf.

21. Bennett D. Three tools available to producers for better furrow irrigation systems. Delta Farm Press. 2014;71(12):26.

22. Tollenaar M, Lee EA. Yield potential, yield stability, and stress tolerance in maize. Field Crop Res. 2002;75(2-3):161-9. doi:10. 1016/S0378-4290(02)00024-2.

23. Wijewardana C, Hock M, Henry B, Reddy KR. Screening corn hybrids for cold tolerance using morphological traits for earlyseason seeding. Crop Sci. 2015;55:851-67. doi:10.2135/ cropsci2014.07.0487.

24.• Wijewardana C, Henry B, Hock M, Reddy KR. Growth and physiological trait variation among corn hybrids for cold tolerance. CJPS-2015-286. Can J Plant Sci. In review. This was a very detailed review of the research mechanisms evaluated related to biotech and agronomic improvements in water conservation.

25. Wijewardana C, Henry B, Reddy KR. Interactive effects on CO2, drought, and ultraviolet-B radiation on maize growth and development. JPHOTOBIOL 2016 5. J Photochem Photobiol B: Biol. In review. 